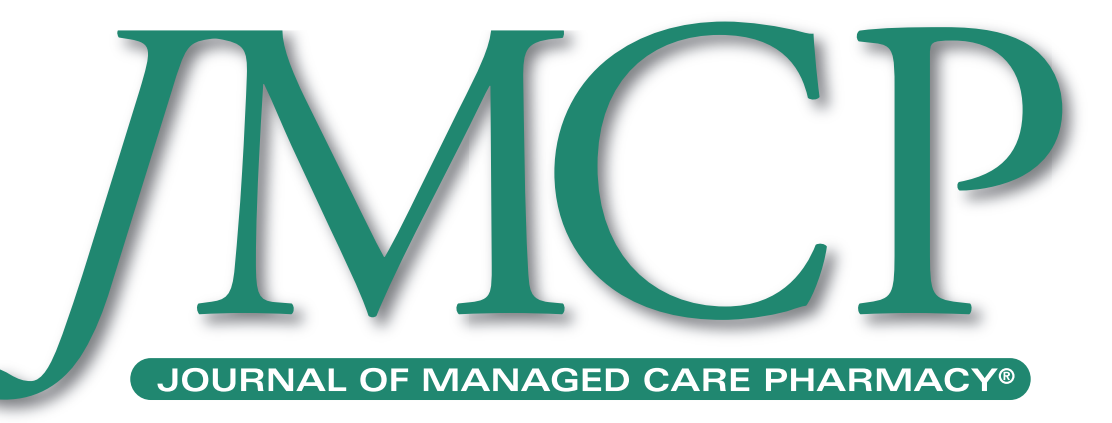

Causes and Consequences of Chronic Kidney Disease: Implications for Managed Health Care

Supplement April 2007

Vol. 13, No. 3 


\section{МСP}

Editor-in-Chief

Frederic R. Curtiss, PhD, RPh, CEBS

(830)935-4319, fcurtiss@amcp.org

Managing Editor

Tamara C. Faggen, (703) 323-0170

tfaggen@amcp.org

Assistant Editor

Diane P. Britton

drbritton@verizon.net

Peer Review Administrator

Jennifer A. Booker, (703) 317-0725

jmcpreview@amcp.org

\section{Graphic Designer}

Laura J. Mahoney, (703) 944-4577

lauramahoney@comcast.net

\section{April Supplement Editor}

Mary Claire Wohletz, PharmD

\section{Account Manager}

Peter Palmer, (856) 795-5777, ext. 13

peter@promedgroup.net

\section{Publisher}

Judith A. Cahill, CEBS

\section{Executive Director}

Academy of Managed Care Pharmacy

This supplement to the Journal of Managed Care Pharmacy. (ISSN 1083-4087) is a publication of the Academy of Managed Care Pharmacy, 100 North Pitt St., Suite 400, Alexandria, VA 22314; (703) 683-8416; (703) 683-8417 (fax).

Copyright $\odot$ 2007, Academy of Managed Care Pharmacy. All rights reserved. No part of this publication may be reproduced or transmitted in any form or by any means, electronic or mechanical, without written permission from the Academy of Managed Care Pharmacy.

POSTMASTER: Send address changes to JMCP, 100 North Pitt St., Suite 400, Alexandria, VA 22314.

\section{Supplement Policy Statement}

\section{Standards for Supplements to the Journal of Managed Care Pharmacy}

Supplements to the Journal of Managed Care Pharmacy are intended to support medical education and research in areas of clinical practice, health care quality improvement, or efficient administration and delivery of health benefits. The following standards are applied to all JMCP supplements to assure quality and assist readers in evaluating potential bias and determining alternate explanations for findings and results.

1. Disclose the principal sources of funding in a manner that permits easy recognition by the reader.

2. Disclose the existence of all potential conflicts of interest among supplement contributors, including financial or personal bias.

3. Describe all drugs by generic name unless the use of the brand name is necessary to reduce the opportunity for confusion among readers.

4. Strive to report subjects of current interest to managed care pharmacists and other managed care professionals. 5. Seek and publish content that does not duplicate content in the Journal of Managed Care Pharmacy.

6. Subject all supplements to expert peer review. 


\title{
Causes and Consequences of Chronic Kidney Disease: Implications for Managed Health Care
}

\author{
Daniel E. Weiner, MD, MS
}

\begin{abstract}
BACKGROUND: Chronic kidney disease (CKD) is a major public health problem that often goes unrecognized until late-stage disease. In the United States, nearly $\mathbf{2 0}$ million people have CKD, and this number is likely to grow as the population ages and the prevalence of diabetes and hypertension rises. With $\$ 28$ billion currently spent on end-stage renal disease care in the United States and with the rapidly expanding dialysis population, it is essential to actively address this epidemic, both by reducing the number of patients who reach kidney failure and by decreasing morbidity and mortality among those with early-stage CKD.
\end{abstract}

OBJECTIVE: To review the burden of CKD and its comorbidities on patients, physicians, and payers and discuss the potential benefits to individual patients and society of identifying and treating earlier stages of CKD.

CONCLUSION: Major steps in dealing with the CKD epidemic are (1) identifying individuals at risk for and with earlier stages of CKD, (2) initiating therapies to slow progression of kidney disease, and (3) treating comorbid conditions associated with CKD, including cardiovascular disease and anemia.

KEYWORDS: Chronic kidney disease, Anemia

J Manag Care Pharm. 2007;13(3)(suppl)S1-S9

\section{Part 1. Overview of Chronic Kidney Disease}

\section{Public Health and Economic Effects}

Chronic kidney disease (CKD) is a progressive condition marked by deteriorating kidney function over time. Typically, kidney function is quantified by glomerular filtration rate (GFR), with GFR most frequently estimated using equations that incorporate serum creatinine along with demographic data. ${ }^{1}$ The early stages of CKD (stages 1 and 2) are manifested by kidney damage and are generally asymptomatic; the kidney functions normally but the risk for progressive disease is significant. As kidney disease worsens, kidney function begins to deteriorate (stages 3 and 4 CKD). Eventually, kidney failure (stage 5 CKD) ensues and kidney replacement therapy is required. ${ }^{2}$

Currently, most people with CKD do not reach kidney failure; rather, they often die prematurely of cardiovascular disease. Therefore, therapeutic goals for CKD include (1) prevention of premature death in earlier stages; (2) prevention of progression to kidney failure and dialysis while maintaining quality of life; and (3) preparation for kidney replacement therapy if it becomes necessary.

In the United States, there is a rising incidence and prevalence of all stages of kidney disease, including kidney failure. Nearly 8 million people (4\% of the adult U.S. population) have moderate or severe CKD, and another 450,000 have end-stage renal disease (ESRD). ${ }^{3}$ These numbers are expected to increase as the population ages and the prevalence of diabetes and hypertension rises, with the ESRD population projected to reach at least 600,000 by $2015 .^{4}$

Major outcomes of CKD include progression to kidney failure and the complications of decreased kidney function, including cardiovascular disease, anemia, and bone disease. Fortunately, interventions are available to reduce the rate of progression of kidney disease and treat the associated complications; but unfortunately, people with CKD are an underdiagnosed and undertreated population.

Progression of kidney disease to ESRD can be slowed if kidney disease is recognized and treated in its earlier stages. Socioeconomic benefits of early CKD identification are

\section{Author}

DANIEL E. WEINER, MD, MS, is an assistant professor of medicine at Tufts University School of Medicine and a staff nephrologist at Tufts-New England Medical Center. He is also the associate medical director of Dialysis Clinics, Inc., Boston.

AUTHOR CORRESPONDENCE: Daniel E. Weiner, MD, MS, Assistant Professor of Medicine, Division of Nephrology, Box \#391, Tufts-New England Medical Center, Boston, MA 02111. Tel: (617) 636-5070; Fax: (617) 636-7890;

E-mail: dweiner@tufts-nemc.org.

Copyright $\odot$ 2007, Academy of Managed Care Pharmacy. All rights reserved. 


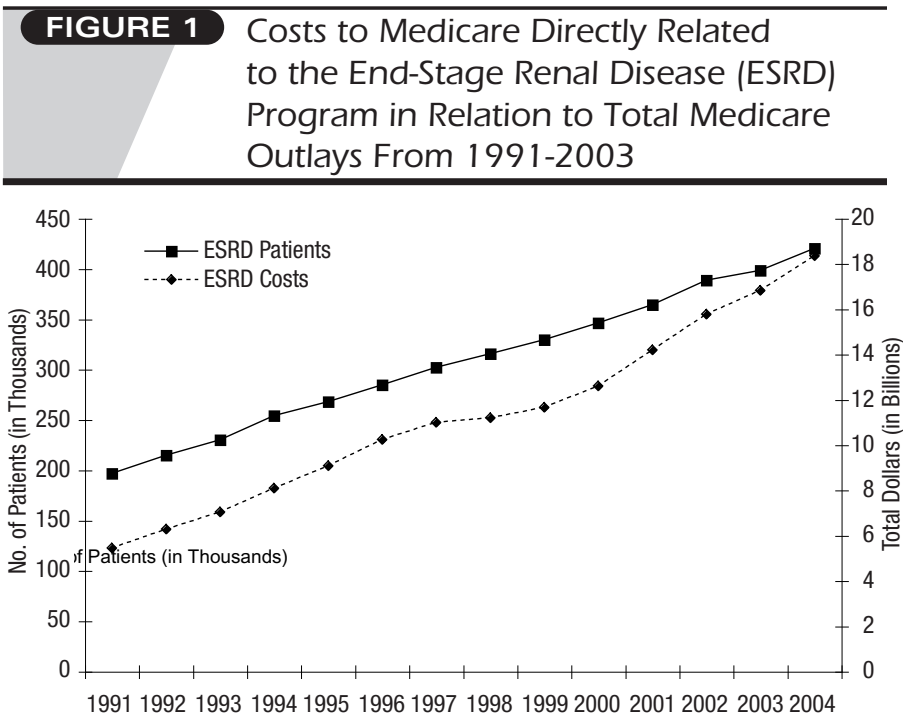

Year

Reproduced from the U.S Renal Data System, USRDS 2005 Annual Data Report. ${ }^{5}$

potentially enormous because kidney failure is accompanied by poor outcomes and much higher financial costs than those for earlier stages of CKD. In 2003, ESRD care cost Medicare and private insurers more than $\$ 27$ billion and accounted for more than $15 \%$ of Medicare expenditures (Figure 1), with direct medical costs per individual approaching $\$ 60,000$ annually and the highest costs occurring in the months around dialysis initiation. ${ }^{5}$

Although Medicare assumes the majority of the financial burden of chronic ESRD care, private insurers spent more than $\$ 9$ billion for ESRD care in 2003. These payments by private insurers are particularly noticable during the initiation period of dialysis since Medicare coverage does not begin until a Medicare-eligible individual who is younger than 65 years has been classified as ESRD for 3 months. For people with private insurance as the primary payer, costs do not shift more fully to Medicare until 33 months have elapsed. Importantly, a recent economic study analyzed the potential cost benefit of delaying CKD progression to ESRD and concluded that if the rate of GFR decline were decreased by only $10 \%$ for individuals with GFR $<60 \mathrm{~mL} / \mathrm{min} / 1.73 \mathrm{~m}^{2}$, the 10 -year savings could approach $\$ 18$ billion to $\$ 20$ billion. $^{6}$

This article reviews the definition and diagnosis of CKD and focuses on chronic medical care for people with CKD. Particular attention is paid to the pathophysiology and prevention of cardiovascular disease and anemia in people with stages 3 and 4 CKD.

\section{Definition and Prevalence of CKD}

To address lack of awareness of CKD among patients and physicians and to improve the quality of CKD care, the National Kidney Foundation (NKF) commissioned the Kidney Disease Outcomes Quality Initiative (KDOQI), and in 2002, clinical guidelines for the evaluation, classification, and stratification of CKD were published. ${ }^{2}$ These guidelines incorporate clinical data and expert opinion to generate treatment recommendations. The guidelines define CKD as either kidney damage or decreased kidney function for 3 or more months. Decreased kidney function is defined by GFR below $60 \mathrm{~mL} / \mathrm{min} / 1.73 \mathrm{~m}^{2}$, while the most common manifestation of kidney damage is the presence of protein in the urine.

The staging system for CKD is described and displayed in Table 1, along with U.S. prevalence data and a treatment plan for each stage. Moderate CKD begins at GFR levels below $60 \mathrm{~mL} / \mathrm{min} / 1.73 \mathrm{~m}^{2}$ and approximates the time at which many of the chronic complications of CKD emerge; the nearly 8 million people with moderate CKD represent a critical treatment opportunity for maintaining quality of life. Importantly, CKD is often asymptomatic until late-stage disease has already developed, making screening of at-risk individuals imperative.

In order to identify individuals with CKD, it is important to accurately estimate GFR. Current clinical standards recommend use of equations that use serum creatinine as well as demographic factors to estimate GFR. ${ }^{2}$ The most commonly used estimating equation is the Modification of Diet in Renal Disease Study equation, which accounts for an individual's age, race, and sex in addition to serum creatinine to estimate GFR. Because serum creatinine levels are influenced by muscle mass and nutrition, dependence on serum creatinine alone can be deceiving, with identical serum creatinine levels representing normal kidney function in some people but significant kidney dysfunction in others. For this reason, the NKF has recommended that clinical laboratories report estimated GFR in addition to serum creatinine. $^{2}$

\section{Etiology of and Risk Factors for CKD}

Major risk factors for development and progression of CKD include diabetes, hypertension, older age, and being African American. Nearly $45 \%$ of incident kidney failure is attributed to diabetes and another $20 \%$ is attributed to chronic hypertension. ${ }^{5}$ Other less common but important causes include primary glomerulonephritis, lupus, and polycystic kidney disease. More than 10 million Americans are diabetic and 40 to 50 million American adults have hypertension, constituting an enormous at-risk population for kidney disease. Notably, diabetes and hypertension are also important risk factors for cardiovascular disease and, to some extent, influence the high incidence of cardiovascular disease in the CKD population.

\section{Awareness of CKD}

In the National Health and Nutrition Examination Survey 19992000 , fewer than $10 \%$ of people with moderately decreased 
TABLE 1 National Kidney Foundation Kidney Disease Outcomes Quality Initiative (NKF-KDOQI) Classification, Prevalence, and Action Plan for CKD*

\begin{tabular}{|c|c|c|c|c|}
\hline CKD Stage $\dagger$ & Description & GFR & Prevalence, $\mathbf{n}(\%)$ & Action Plan \\
\hline- & Increased risk & $\geq 60$ with CKD risk factors & - & Screening, risk reduction \\
\hline 1 & Kidney damage, normal GFR & $\geq 90$ & $5,900,000(3.3)$ & $\begin{array}{l}\text { Diagnosis, treat comorbidities, } \\
\text { slow progression }\end{array}$ \\
\hline 2 & $\begin{array}{l}\text { Kidney damage, mild } \\
\text { decreased GFR }\end{array}$ & $60-89$ & $5,300,000(3.0)$ & Assess progression \\
\hline 3 & Moderate CKD & $30-59$ & $7,600,000(4.3)$ & Evaluate and treat complications \\
\hline 4 & Severe CKD & $15-29$ & $400,000(0.2)$ & $\begin{array}{l}\text { Prepare for kidney replacement } \\
\text { therapy }\end{array}$ \\
\hline 5 & Kidney Failure & $<15$ or dialysis & $300,000(0.1)$ & Kidney replacement therapy \\
\hline \multicolumn{5}{|c|}{$\begin{array}{l}\text { * Adapted from KDOQI Clinical Practice Guidelines for Chronic Kidney Disease: Evaluation, Classification, and Stratification. }{ }^{2} \\
+ \text { Prevalence data for stages } 1-4 \text { are derived from NHANES III data while stage } 5 \text { data is from the U.S. Renal Data System. The action plan for each stage also includes actions } \\
\text { from the prior stage. } \\
\text { CKD =chronic kidney disease; GFR }=\text { estimated glomerular filtration rate }\left(\mathrm{mL} / \mathrm{min} / 1.73 \mathrm{~m}^{2}\right) ; \text { NHANES III=Third National Health and Nutrition Examination Survey. }\end{array}$} \\
\hline
\end{tabular}

kidney function (stage $3 \mathrm{CKD}$ ) reported ever being told that they had "weak or failing kidneys." In particular, older women were more often unaware of their kidney disease, likely reflecting the fact that normal-appearing levels of serum creatinine can be consistent with significantly impaired kidney function. ${ }^{8}$ This finding highlights the importance of using GFR estimating equations that incorporate age and sex as variables, particularly because the lack of awareness of CKD also extends to health care professionals, as demonstrated by infrequent testing for CKD in at-risk individuals. ${ }^{9}$

Additionally, patients with CKD often may be undertreated. For example, in a recent study of patients with acute myocardial infarction, patients with CKD were far less likely to receive reperfusion therapy at admission and beta-blocking agents and aspirin at hospital discharge. ${ }^{10}$ Other studies have shown inadequate blood pressure control in CKD patients despite the fact that reducing systolic blood pressure is one of the tenets of preventing CKD progression. ${ }^{11,12}$ Lack of awareness of CKD also results in late referral to a nephrologist for specialty care, with consequences that include inadequate control of comorbid conditions and incomplete preparation for kidney replacement therapy; in particular, reliance on catheters for dialysis initiation. $^{13,14}$

\section{Initiatives to Improve CKD Management}

In light of the high societal burden of CKD and the lack of recognition of CKD and its complications, several public health initiatives have been launched to improve awareness of CKD, with NKF and the National Institutes of Health (NIH) assuming major roles. These include the KDOQI guidelines, which may be viewed at http://www.kidney.org/professionals/kdoqi/guidelines. $\mathrm{cfm}$. The NKF and the international nephrology community are collaborating on the global Kidney Disease Improving Global
Outcomes initiative. Additionally, NKF sponsors the national Kidney Early Evaluation Program, which provides community screening for kidney disease by medical professionals. NIH, through the National Kidney Disease Education Program, has undertaken initiatives to develop national standards for accuracy and equivalency in serum creatinine measurements, to improve and refine GFR estimating equations, and to educate patients and providers on CKD.

\section{Part 2. Sequelae of Chronic Kidney Disease}

Essential to treating patients with CKD is recognizing and managing the sequelae of progressive kidney failure. This process begins with the recognition of CKD as described above, and as described in the action plan for CKD, continues with CKD stage-specific assessment of modifiable risk factors. ${ }^{2}$ At the onset of stage $3 \mathrm{CKD}\left(\mathrm{GFR}<60 \mathrm{~mL} / \mathrm{min} / 1.73 \mathrm{~m}^{2}\right.$ ), many of these complications may begin to develop. Major sequelae of CKD include (1) continued progression of CKD and development of kidney failure requiring kidney replacement therapy, (2) development and/or progression of cardiovascular disease, (3) anemia, and (4) bone disease. The remainder of this article will focus on progression of CKD, cardiovascular disease, and anemia, emphasizing sequelae with potential therapeutic options. Although the pathophysiology, diagnosis, and management of the mineral and bone disorders of CKD are of considerable importance, the complexity of evidence within this topic renders it a subject that requires more discussion than can be provided in this article.

\section{Progression of CKD}

Perhaps the most important complication of CKD is progressive kidney function decline, resulting in either death or need for kidney replacement therapy, including dialysis. In fact, 
FIGURE 2 Conceptual Illustration Depicting the Effects of Varying Progression Rates in Chronic Kidney Disease

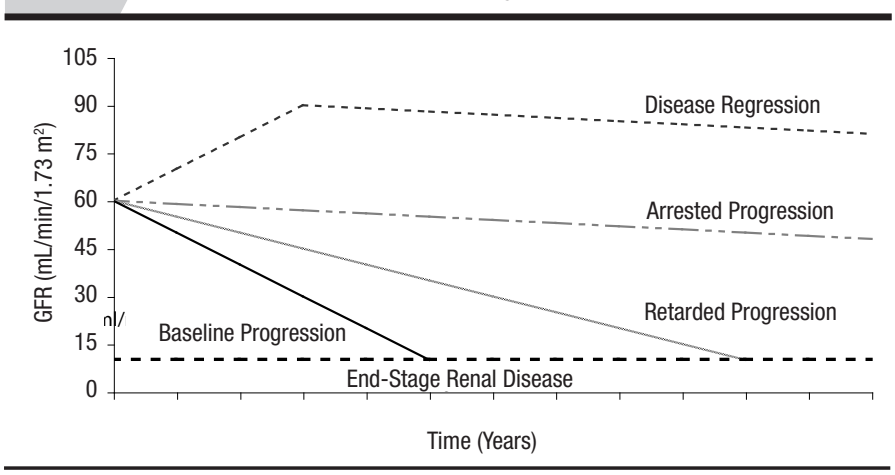

"Disease Regression" portrays a return to near-normal glomerular filtration rate (GFR), consistent with treated lupus or membranous nephropathy.

"Arrested Progression" portrays progression rates of $1 \mathrm{~mL} / \mathrm{min} / 1.73 \mathrm{~m}^{2}$ per year, consistent with normal aging.

"Retarded Progression" portrays progression rates of $5 \mathrm{~mL} / \mathrm{min} / 1.73 \mathrm{~m}^{2}$ per year, potentially consistent with treated diabetic nephropathy.

"Baseline Progression" portrays progression rates of $10 \mathrm{~mL} / \mathrm{min} / 1.73 \mathrm{~m}^{2}$ per year, consistent with untreated diabetic nephropathy.

Reproduced and modified with permission from Jaber et al. ${ }^{16}$

premature death is a far more common result of CKD than is kidney failure, with both cardiovascular and noncardiovascular mortality rates increasing as kidney function declines. ${ }^{15}$ However, treatment of CKD can reduce the rate of kidney function decline from as much as $10 \mathrm{~mL} / \mathrm{min} / 1.73 \mathrm{~m}^{2}$ per year in untreated diabetic nephropathy to 2 to $4 \mathrm{~mL} / \mathrm{min} / 1.73 \mathrm{~m}^{2}$ per year, with dramatic effects on patient outcomes, including decreased ESRD and mortality rates (Figure 2). ${ }^{16}$

Angiotensin-converting enzyme inhibitors (ACEIs) and angiotensin receptor blockers are proven to slow the rate of progression of kidney disease and may reduce the societal costs associated with kidney disease. ${ }^{17-22}$ These medications are particularly effective in individuals with proteinuric kidney disease; important kidney diseases with proteinuria include diabetes mellitus, primary glomerular diseases, and most cases of hypertensive nephropathy. Beyond blockade of the reninangiotensin-aldosterone system and blood pressure control, other factors shown to reduce progression of kidney disease include intensive hyperglycemia management and smoking cessation. ${ }^{23-25}$ Early management of anemia as well as use of HMG CoA reductase inhibitors (statins) may also reduce progression. ${ }^{26,27}$ These are discussed in more detail below.

\section{Cardiovascular Disease}

\section{Pathogenesis and Epidemiology}

Much of the increased burden of chronic disease in CKD is due to increased prevalence of both traditional and nontraditional cardiovascular disease risk factors. Traditional risk factors are those factors identified in the Framingham Heart Study as conferring increased risk of cardiovascular disease in the general population. These traditional risk factors include older age, diabetes, and hypertension, all of which are highly prevalent in patients with CKD. Nontraditional risk factors are defined as those factors that increase in prevalence as kidney function declines and that have been hypothesized to be cardiovascular disease risk factors in patients with CKD. These include anemia, inflammation, and abnormal calcium and phosphate metabolism (Table 2). ${ }^{28}$

Most cardiovascular disease risk factors lead to atherosclerosis, arteriosclerosis, cardiomyopathy, or any combination of these conditions. Atherosclerosis, defined as an occlusive disease of the vasculature due to the deposition of lipid-laden plaques, and arteriosclerosis, defined as nonocclusive remodeling of the vasculature accompanied by a loss of arterial elasticity, may manifest as ischemic heart disease and heart failure. Certain risk factors, including dyslipidemia, primarily predispose an individual to development and progression of atherosclerosis, while others, including volume overload and elevated calciumphosphorus product, may predispose one to arteriosclerosis. Still other risk factors, including anemia, may predispose an individual to cardiac remodeling and left ventricular hypertrophy (LVH). Essential to the understanding of cardiovascular disease in CKD is an understanding of the interplay of these various risk factors in patients with kidney disease, and these are discussed in more detail below.

CKD is an important risk factor for cardiovascular disease. Notably, far more patients with CKD die of cardiovascular disease than of kidney failure. The situation does not improve in patients on dialysis, where mortality due to cardiovascular disease is 10 to 30 times higher in dialysis patients than in agematched individuals in the general population (Figure 3).28,29 Similarly, people with earlier-stage CKD have a higher prevalence of cardiovascular disease risk factors than do those without CKD and have higher cardiovascular disease event rates (Figure 4). ${ }^{30-33}$ Therefore, both NKF and the Joint National Committee on Prevention, Detection, Evaluation, and Treatment of High Blood Pressure in the most recent hypertension guidelines have classified CKD as a cardiovascular disease risk equivalent. ${ }^{2,34}$ The impact of this recommendation is uncertain. ${ }^{35,36}$

Several studies have demonstrated that in patients with cardiovascular disease or at high risk for cardiovascular disease, the presence of CKD is an independent risk factor for future cardiovascular disease outcomes. ${ }^{31,32,37-41}$ This has also been demonstrated in lower-risk community-based cohorts, albeit less consistently. ${ }^{33,42}$ The enhanced risk for cardiovascular disease outcomes is likely multifactorial and related to both traditional and nontraditional cardiovascular disease risk factors. It is likely that the interplay between CKD and cardiovascular disease risk factors, including diabetes, hypertension, anemia, 


\section{TABLE 2 Traditional and Nontraditional Risk Factors for Development of Cardiovascular Disease in Individuals With CKD*}

\begin{tabular}{ll}
\hline Traditional Risk Factors & Nontraditional Factors \\
\hline Older age & Albuminuria \\
Male gender & Homocysteine \\
Hypertension & Lipoprotein (a) and apo (a) isoforms \\
Higher LDL-C & Lipoprotein remnants \\
Lower HDL-C & Anemia \\
Diabetes & Abnormal calcium/phosphate \\
Smoking & metabolism \\
Physical inactivity & Extracellular fluid volume overload \\
Menopause & Electrolyte imbalance \\
Family history of cardiovascular & Oxidative stress \\
disease & Inflammation (C-reactive protein) \\
Left ventricular hypertrophy & Malnutrition \\
Sleep disturbances & Thrombogenic factors \\
& Altered nitric oxide/endothelin \\
& balance \\
\hline *Adapted from Sarnak et al. ${ }^{28}$ & \\
$C K D=$ chronic kidney disease; HDL-C $=$ high-density lipoprotein cholesterol; \\
LDL-C=low-density lipoprotein cholesterol.
\end{tabular}

and inflammation, leads to enhanced cardiovascular risk. This hypothesis, dubbed the "cardiorenal syndrome," attempts to explain the increased risk of cardiac outcomes in patients with CKD ${ }^{43}$ Other possibilities are that CKD may be a marker of the duration and severity of known risk factors (e.g., diabetes, hypertension), and CKD may identify individuals with undiagnosed vascular disease. ${ }^{44}$ Finally, patients with CKD may not receive sufficient therapy for their disease, including medications such as aspirin, beta-blockers, and ACEIs, as well as diagnostic and therapeutic procedures. ${ }^{10}$

\section{Treatment}

Attempts to modify cardiovascular risk once an individual has reached dialysis have been discouraging. The largest study to date in dialysis patients, the 4D trial, randomized diabetic hemodialysis patients to lipid-lowering therapy with atorvastatin versus placebo. While all adequately powered trials in the general population have shown a survival benefit to statin use in high-risk cardiovascular disease populations, the 4D trial demonstrated no benefit to statin therapy for hemodialysis patients. ${ }^{45}$ Although 2 other randomized controlled trials are examining lipidlowering in earlier stages of $\mathrm{CKD},{ }^{46,47}$ post hoc studies that have analyzed lipid-lowering therapy in patients with CKD enrolled in larger cardiovascular trials and smaller CKD studies have generally shown a significant benefit to these therapies. ${ }^{48-51}$ Until results of further randomized trials are available, these data suggest that intervention needs to be focused on the earlier-stage CKD population, with initiation well before an individual requires dialysis.

\section{Anemia}

\section{Pathogenesis and Epidemiology}

The kidneys are the primary source of erythropoietin in adults. A drop in blood oxygen levels detected within the kidney stimulates the release of erythropoietin. In normal physiology, erythropoietin stimulates red blood cell production, and oxygencarrying capacity of blood returns toward normal. However, as kidney disease progresses, the production of erythropoietin declines and the body is less able to maintain a normal red blood cell count. In fact, anemia can develop relatively early in CKD, with significant declines in hemoglobin seen at estimated creatinine clearances (similar to eGFR) below $70 \mathrm{~mL} /$ min in men and below $50 \mathrm{~mL} / \mathrm{min}$ in women. In the United States, it is estimated that 1.2 million women and 390,000 men have hemoglobin below $12 \mathrm{~g} / \mathrm{dL}$ associated with $\mathrm{CKD} .{ }^{52}$ Most commonly, anemia is corrected with administration of recombinant erythropoietin. However, despite the widespread availability of recombinant erythropoietin, predialysis anemia therapy likely remains inadequate. ${ }^{53}$ In 2003, incident hemodialysis patients had mean hemoglobin of $9.5 \mathrm{~g} / \mathrm{dL}$-well below the current KDOQI recommended minimum level of 11 g/dL (Figure 5) —and only one third of incident hemodialysis patients were receiving erythropoietin therapy at dialysis initiation. ${ }^{5,54}$ This may be related to insufficient education and predialysis testing because less than half of Medicare patients with CKD have anemia testing that includes iron studies within 2 years of initiating chronic dialysis. ${ }^{55}$ Importantly, to date, no randomized controlled trials have demonstrated any benefit on cardiovascular or mortality outcomes associated with targeting hemoglobin levels $>11-12 \mathrm{~g} / \mathrm{dL}$ in patients with CKD, including those on dialysis. ${ }^{56-58}$

\section{Sequelae of Anemia}

Anemia can have multiple effects in individuals with CKD Anemia has been associated with reduced quality of life, and higher hemoglobin levels are an important predictor of improved quality of life in individuals with stage $4 \mathrm{CKD} .{ }^{59}$ In dialysis patients, higher hematocrit has also been associated with improved cognitive functioning; notably, this has not been studied in the predialysis CKD population. ${ }^{60}$

Anemia is classified as a nontraditional risk factor for cardiovascular disease, meaning that it may be associated with cardiovascular disease and becomes more prominent as CKD progresses. This may be due to the relationship between anemia and cardiac remodeling. Volume overload may occur when blood volume increases to compensate for decreased oxygen-carrying capacity, as seen with anemia. Chronic volume overload will cause the heart to remodel, as the left ventricle hypertrophies in order to increase cardiac output. ${ }^{61,62}$ As the ventricle grows, it requires an increased blood supply to feed its greater needs; however, this increase often may not occur due to underlying illness, with the result of decreased subendocardial perfusion. 


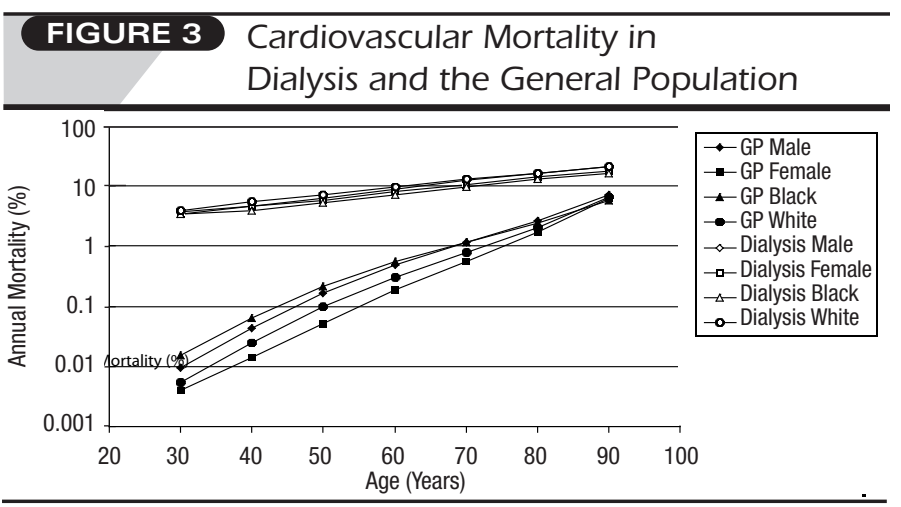

Comparisons of cardiovascular disease death at a given age in the general population (GP) and the end-stage renal disease population. Reproduced with permission from Sarnak and Levey. ${ }^{29}$

\section{FIGURE 4 Smoothed Figures for Cardiac Event Rates in Individuals With No Known History of Cardiovascular Disease}
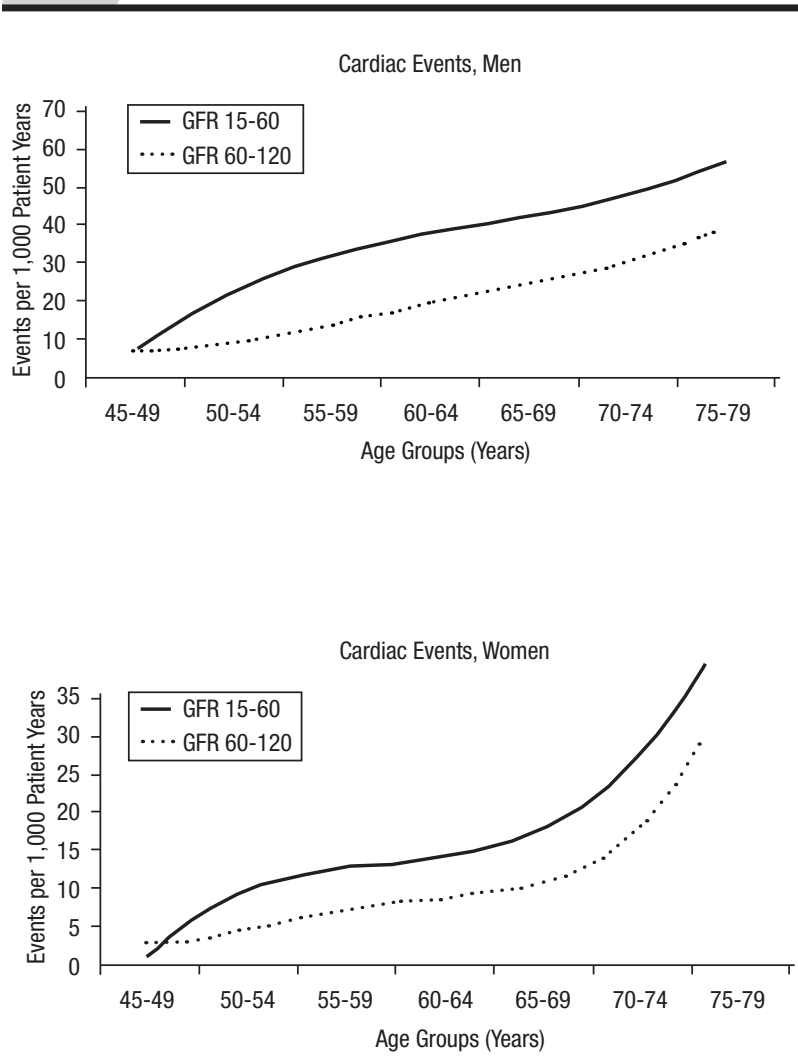

Trend lines were based on a polynomial model with 2 knots, and data was derived from individuals enrolled in the Atherosclerosis Risk in Communities Study and the Cardiovascular Health Study. Cardiac outcomes include myocardial infarction and fatal coronary disease. Glomerular filtration rate (GFR) is estimated from calibrated serum creatinine values using the 4-variable Modification of Diet in Renal Disease equation with methods and definitions described by Weiner et al. ${ }^{33}$
This condition may cause inadequate oxygen supply, resulting in myocardial fibrosis and myocyte death. The end-point of this cycle can be dilated cardiomyopathy and overt heart failure. ${ }^{63}$ Accordingly, a study by Levin et al. identified LVH in 25\% to $45 \%$ of patients with CKD, with higher prevalence as kidney function worsened. They also found an independent association between reduced hemoglobin and $\mathrm{LVH} .{ }^{64}$

Observational studies have demonstrated interesting associations between anemia, $\mathrm{CKD}$, and adverse events. One study found a synergistic relationship between anemia and LVH in patients with predominantly stage $3 \mathrm{CKD}$, such that they were at markedly increased risk of cardiac events and death. ${ }^{65}$ Other studies have found that anemia is a significant risk factor for stroke, cardiac events, and mortality in patients with CKD and, in particular, in patients with diabetic kidney disease. ${ }^{66-70}$

Inadequate anemia management in patients with CKD may be associated with higher health care costs. While patients with CKD on erythropoietin therapy had slightly higher costs in the 2 years before dialysis initiation, those who were not on erythropoietin had a dramatic spike in costs around the time of dialysis initiation that exceeded the cost of early erythropoietin therapy ${ }^{71}$ Whether this spike is related to erythropoietin itself or reflects the overall quality of predialysis care is uncertain.

\section{Treatment}

The 2006 guidelines from NKF recommend maintaining hemoglobin levels $>11 \mathrm{~g} / \mathrm{dL}$ but not to exceed $13 \mathrm{~g} / \mathrm{dL}$, with use of recombinant erythropoietin and iron as needed. ${ }^{54}$ It is likely that future updates to these guidelines will recommend an upper limit for target hemoglobin levels, perhaps in the range of 12.0-12.5 g/dL; however, an upper limit remains a controversial issue as there is considerable fluctuation in hemoglobin levels despite stable maintenance doses of recombinant erythropoietin and iron, making guidelines that limit hemoglobin levels to a tight range (e.g., 11-12 g/dL) extremely difficult to consistently achieve. $^{72}$ The clinical practice guidelines further recommend an annual assessment for anemia, at minimum, in CKD (nonESRD) patients. Notably, in patients with both CKD and anemia, measurement of erythropoietin levels are not routinely useful in distinguishing erythropoietin deficiency from other causes of anemia in clinical settings and therefore are not recommended. ${ }^{54}$ Currently available erythropoiesis-stimulating agents in the United States include Epoetin alfa and darbepoetin alfa.

Adequate iron stores are essential for erythropoiesis, and the clinical practice guidelines also stress measurement of ferritin and transferrin saturation before initiation of erythropoiesisstimulating agents. ${ }^{54}$ While there is no agreed-on consensus for level of transferrin saturation that predisposes to erythropoietin resistance, ferritin levels below $25 \mathrm{ng} / \mathrm{mL}$ in men and below $12 \mathrm{ng} / \mathrm{mL}$ in women suggest that iron deficiency may contribute to anemia. Intravenous and oral iron formulations are important adjuncts to erythropoiesis-stimulating agents to address 
erythropoietin resistance secondary to iron deficiency.

The NKF anemia guideline is primarily opinion based, and recent randomized trials have failed to demonstrate benefit associated with targeting hemoglobin levels $>12 \mathrm{~g} / \mathrm{dL}$. A recent randomized trial comparing a low hemoglobin arm (goal: 9.0$10.5 \mathrm{~g} / \mathrm{dL}$ ) with a higher hemoglobin arm (goal: $12-14 \mathrm{~g} / \mathrm{dL}$, the treatment group) in Canadians with stage 3 to 4 CKD failed to show regression of left ventricular mass in the treatment group. However, there was significantly higher blood pressure in the treatment group during follow-up, and planned differences in hemoglobin levels between the treatment and control groups were not achieved. ${ }^{73}$

The results of 2 randomized nonblinded studies of anemia management in CKD have recently been published. The Cardiovascular Risk Reduction by Early Anemia Treatment with Epoetin beta (CREATE) Trial compared the effects of partially corrected anemia (hemoglobin target level 10.5-11.5 g/dL) with "normalization" of hemoglobin (target level 13.0-15.0 g/dL) on cardiovascular events in 605 people with baseline estimated creatinine clearance of $15-35 \mathrm{~mL} / \mathrm{min} .{ }^{58}$ Over 3 years, there was no significant difference between groups in mortality, left ventricular mass index, or number of patients progressing to dialysis. Major differences were seen in quality-of-life measures, with the higher hemoglobin group experiencing improved general health and vitality. The Correction of Anemia and Outcomes in Renal Insufficiency (CHOIR) Trial compared the effects of partially corrected anemia (hemoglobin target level $11.3 \mathrm{~g} / \mathrm{dL}$ ) with "normalization" of hemoglobin (target level 13.5 $\mathrm{g} / \mathrm{dL}$ ) on a composite outcome of all-cause mortality, myocardial infarction, heart failure hospitalization, and stroke in 1,432 people in the United States with mean estimated GFR of $27 \mathrm{~mL} /$ $\mathrm{min} / 1.73 \mathrm{~m}^{2} .{ }^{57}$ Despite mean weekly doses of Epoetin alfa that exceeded 11,000 units, the high-hemoglobin arm only achieved a mean hemoglobin level of $12.6 \mathrm{~g} / \mathrm{dL}$. A small increased risk of the composite outcome was noted for the high-hemoglobin target group with no quality of life benefit seen with higher hemoglobin targets.

Taken in sum, these studies generally do not support attempts to persistently target hemoglobin beyond the 11-12 $\mathrm{g} / \mathrm{dL}$ range. Other studies of erythropoiesis-stimulating agents are ongoing. These trials are necessary to further delineate the costs and benefits of attaining this goal in people with CKD and will need to further account for the role of inflammation, iron administration, and bone marrow resistance to erythropoietin in anemia therapy in CKD.

\section{Conclusions}

CKD is a major public health issue in the United States with considerable socioeconomic and medical significance. The incidence of CKD is expected to increase as the population ages and the prevalence of diabetes and hypertension rises, yet many people are unaware they have reduced kidney function. Earlier

\section{FIGURE 5 Mean Hemoglobin Levels at the Initiation of Kidney Replacement Therapy, by Gender}

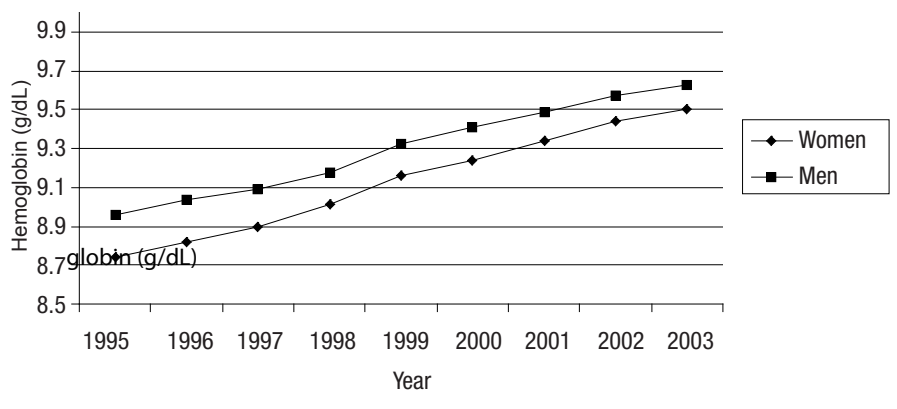

Data from the U.S. Renal Data System, USRDS 2005 Annual Data Report. ${ }^{5}$

identification of CKD accompanied by aggressive treatment consisting of well-known therapies holds the potential to slow progression to kidney failure and prevent development of sequelae, including cardiovascular disease and premature death. Managing the comorbid conditions associated with $\mathrm{CKD}$, including hypertension, diabetes, cardiovascular disease, and anemia, is essential for optimal patient management and slowing of CKD progression as well as for judicious use of health care dollars. Improving the management of patients with CKD requires education and action by all facets of the health care system, including patients, physicians, researchers, and payers.

\section{ACKNOWLEDGMENTS}

Some data reported in this article have been supplied by the U.S. Renal Data System. The interpretation and reporting of these data are the responsibility of the author and in no way should be seen as an official policy or interpretation of the U.S. government. KDOQI is a trademark of the National Kidney Foundation.

\section{DISCLOSURE}

Author Daniel E. Weiner has received funding from Amgen Inc., Thousand Oaks, California, for research into the relationship between cardiovascular disease and chronic kidney disease. Although this article was written at the request of Amgen Inc., it was written entirely by Weiner, who had sole discretion over its content. He received no payment for his work on this article.

\section{REFERENCES}

1. Stevens LA, Coresh J, Greene T, Levey AS. Assessing kidney function-measured and estimated glomerular filtration rate. N Engl J Med. 2006;354(23):2473-83.

2. NKF-KDOQI, Clinical practice guidelines for chronic kidney disease: evaluation, classification, and stratification. Am J Kidney Dis. 2002;39(2 suppl 1): S1-S266.

3. Coresh J, Astor BC, Greene T, Eknoyan G, Levey AS. Prevalence of chronic kidney disease and decreased kidney function in the adult U.S. population: Third National Health and Nutrition Examination Survey. Am J Kidney Dis. 2003;41(1):1-12. 
4. Gilbertson DT, Liu J, Xue JL, et al. Projecting the number of patients with end-stage renal disease in the United States to the year 2015. J Am Soc Nephrol. 2005;16(12):3736-41.

5. U.S. Renal Data System. USRDS 2005 Annual Data Report: Atlas of End-Stage Renal Disease in the United States. Bethesda, MD: National Institutes of Health, National Institute of Diabetes and Digestive and Kidney Diseases; 2005.

6. Trivedi HS, Pang MM, Campbell A, Saab P. Slowing the progression of chronic renal failure: economic benefits and patients' perspectives. Am J Kidney Dis. 2002;39(4):721-29.

7. Coresh J, Byrd-Holt D, Astor BC, et al. Chronic kidney disease awareness, prevalence, and trends among U.S. adults, 1999 to 2000. J Am Soc Nephrol. 2005; 16(1):180-88.

8. Nickolas TL, Frisch GD, Opotowsky AR, Arons R, Radhakrishnan J. Awareness of kidney disease in the US population: findings from the National Health and Nutrition Examination Survey (NHANES) 1999 to 2000. Am J Kidney Dis. 2004:44(2): 185-97

9. Stevens LA, Fares G, Fleming J, et al. Low rates of testing and diagnostic codes usage in a commercial clinical laboratory: evidence for lack of physician awareness of chronic kidney disease. J Am Soc Nephrol. 2005;16(8):2439-48.

10. Wright RS, Reeder GS, Herzog CA, et al. Acute myocardial infarction and renal dysfunction: a high-risk combination. Ann Intern Med. 2002;137(7):563-70.

11. Peralta CA, Hicks LS, Chertow GM, et al. Control of hypertension in adults with chronic kidney disease in the United States. Hypertension. 2005; 45(6):1119-24

12. Sarnak MJ, Greene T, Wang X, et al. The effect of a lower target blood pressure on the progression of kidney disease: long-term follow-up of the modification of diet in renal disease study. Ann Intern Med. 2005;142(5): 342-51

13. Winkelmayer WC, Owen WF, Jr., Levin R, Avorn J. A propensity analysis of late versus early nephrologist referral and mortality on dialysis. J Am Soc Nephrol. 2003; 14(2):486-92.

14. Kinchen KS, Sadler J, Fink N, et al. The timing of specialist evaluation in chronic kidney disease and mortality. Ann Intern Med. 2002;137(6):479-86.

15. Keith DS, Nichols GA, Gullion CM, Brown JB, Smith DH. Longitudinal follow-up and outcomes among a population with chronic kidney disease in a large managed care organization. Arch Intern Med. 2004;164(6):659-63.

16. Jaber BL, Madias NE. Progression of chronic kidney disease: can it be prevented or arrested? Am J Med. 2005;118(12):1323-30.

17. Lewis EJ, Hunsicker LG, Bain RP, Rohde RD. The effect of angiotensinconverting-enzyme inhibition on diabetic nephropathy. The Collaborative Study Group. N Engl J Med. 1993;329(20):1456-62.

18. Jafar TH, Schmid CH, Landa M, et al. Angiotensin-converting enzyme inhibitors and progression of nondiabetic renal disease. A meta-analysis of patient-level data. Ann Intern Med. 2001;135(2):73-87.

19. Brenner BM, Cooper ME, de Zeeuw D, et al. Effects of losartan on renal and cardiovascular outcomes in patients with type 2 diabetes and nephropathy. N Engl J Med. 2001;345(12):861-69.

20. Herman WH, Shahinfar S, Carides GW, et al. Losartan reduces the costs associated with diabetic end-stage renal disease: the RENAAL study economic African American evaluation. Diabetes Care. 2003;26(3):683-87.

21. Rosen AB, Hamel MB, Weinstein MC, Cutler DM, Fendrick AM, Vijan S. Cost-effectiveness of full Medicare coverage of angiotensin-converting enzyme inhibitors for beneficiaries with diabetes. Ann Intern Med. 2005;143(2):89-99.

22. Klahr S, Levey AS, Beck GJ, et al. The effects of dietary protein restriction and blood-pressure control on the progression of chronic renal disease. Modification of Diet in Renal Disease Study Group. N Engl J Med. 1994;330(13):877-84.

23. The effect of intensive treatment of diabetes on the development and progression of long-term complications in insulin-dependent diabetes mellitus. The Diabetes Control and Complications Trial Research Group. N Engl J Med. 1993:329(14):977-86.

24. Orth SR, Ritz E, Schrier RW. The renal risks of smoking. Kidney Int. 1997; 51(6):1669-77.
25. Orth SR, Schroeder T, Ritz E, Ferrari P. Effects of smoking on renal function in patients with type 1 and type 2 diabetes mellitus. Nephrol Dial Transplant. 2005;20(11):2414-19

26. Gouva C, Nikolopoulos P, Ioannidis JP, Siamopoulos KC. Treating anemia early in renal failure patients slows the decline of renal function: a randomized controlled trial. Kidney Int. 2004;66(2):753-60.

27. Tonelli M, Moye L, Sacks FM, Cole T, Curhan GC. Effect of pravastatin on loss of renal function in people with moderate chronic renal insufficiency and cardiovascular disease. J Am Soc Nephrol. 2003;14(6):1605-13.

28. Sarnak MJ, Levey AS, Schoolwerth AC, et al. Kidney disease as a risk factor for development of cardiovascular disease: a statement from the American Heart Association Councils on Kidney in Cardiovascular Disease, High Blood Pressure Research, Clinical Cardiology, and Epidemiology and Prevention. Hypertension. 2003:42:1050-65.

29. Sarnak MJ, Levey AS. Cardiovascular disease and chronic renal disease: a new paradigm. Am J Kidney Dis. 2000;35(4 suppl 1):S117-31.

30. Henry RM, Kostense PJ, Bos G, et al. Mild renal insufficiency is associated with increased cardiovascular mortality: The Hoorn Study. Kidney Int. 2002;62(4):1402-07.

31. Shlipak MG, Heidenreich PA, Noguchi H, Chertow GM, Browner WS, McClellan MB. Association of renal insufficiency with treatment and outcomes after myocardial infarction in elderly patients. Ann Intern Med. 2002;137(7):555-62.

32. Shlipak MG, Simon JA, Grady D, Lin F, Wenger NK, Furberg CD. Renal insufficiency and cardiovascular events in postmenopausal women with coronary heart disease. J Am Coll Cardiol. 2001;38(3):705-11.

33. Weiner DE, Tighiouart $\mathrm{H}, \mathrm{Amin} \mathrm{MG}$, et al. Chronic kidney disease as a risk factor for cardiovascular disease and all-cause mortality: a pooled analysis of community-based studies. J Am Soc Nephrol. 2004;15(5):1307-15.

34. Chobanian AV, Bakris GL, Black HR, et al. The Seventh Report of the Joint National Committee on Prevention, Detection, Evaluation, and Treatment of High Blood Pressure: the JNC 7 report. JAMA. 2003;289(19):2560-72.

35. Hyre AD, Fox CS, Astor BC, Cohen AJ, Muntner P. The impact of reclassifying moderate $\mathrm{CKD}$ as a coronary heart disease risk equivalent on the number of US adults recommended lipid-lowering treatment. Am J Kidney Dis. 2007;49(1):37-45

36. Tonelli M. Should CKD be a coronary heart disease risk equivalent? Am J Kidney Dis. 2007:49(1):8-11.

37. Dries DL, Exner DV, Domanski MJ, Greenberg B, Stevenson LW. The prognostic implications of renal insufficiency in asymptomatic and symptomatic patients with left ventricular systolic dysfunction. J Am Coll Cardiol. 2000;35(3):681-89.

38. Mann JF, Gerstein HC, Pogue J, Bosch J, Yusuf S. Renal insufficiency as a predictor of cardiovascular outcomes and the impact of ramipril: the HOPE randomized trial. Ann Intern Med. 2001;134(8):629-36.

39. Manjunath G, Tighiouart $H$, Coresh J, et al. Level of kidney function as a risk factor for cardiovascular outcomes in the elderly. Kidney Int. 2003;63(3):1121-29.

40. Manjunath G, Tighiouart H, Ibrahim H, et al. Level of kidney function as a risk factor for atherosclerotic cardiovascular outcomes in the community. J Am Coll Cardiol. 2003;41(1):47-55.

41. Weiner DE, Tighiouart H, Stark PC, et al. Kidney disease as a risk factor for recurrent cardiovascular disease and mortality. Am J Kidney Dis. 2004; 44(2): 198-206.

42. Go AS, Chertow GM, Fan D, McCulloch CE, Hsu CY. Chronic kidney disease and the risks of death, cardiovascular events, and hospitalization. N Engl J Med. 2004;351(13):1296-305.

43. Keane WF. Metabolic pathogenesis of cardiorenal disease. Am J Kidney Dis 2001;38(6):1372-75.

44. Weiner DE, Tabatabai S, Tighiouart H, et al. Cardiovascular outcomes and all-cause mortality: exploring the interaction between CKD and cardiovascular disease. Am J Kidney Dis. 2006;48(3):392-401. 
45. Wanner C, Krane V, Marz W, et al. Atorvastatin in patients with type 2 diabetes mellitus undergoing hemodialysis. N Engl J Med. 2005;353(3):238-48.

46. Baigent C, Landry M. Study of Heart and Renal Protection (SHARP). Kidney Int Suppl. 2003(84):S207-S210.

47. Fellstrom BC, Holdaas H, Jardine AG. Why do we need a statin trial in hemodialysis patients? Kidney Int Suppl. 2003(63):S204-S206.

48. Tonelli M, Moye L, Sacks FM, Kiberd B, Curhan G. Pravastatin for secondary prevention of cardiovascular events in persons with mild chronic renal insufficiency. Ann Intern Med. 2003;138(2):98-104.

49. Athyros VG, Mikhailidis DP, Papageorgiou AA, et al. The effect of statins versus untreated dyslipidaemia on renal function in patients with coronary heart disease. A subgroup analysis of the Greek atorvastatin and coronary heart disease evaluation (GREACE) study. J Clin Pathol. 2004;57(7):728-34.

50. Fried LF, Orchard TJ, Kasiske BL. Effect of lipid reduction on the progression of renal disease: a meta-analysis. Kidney Int. 2001;59(1):260-69.

51. Bianchi S, Bigazzi R, Caiazza A, Campese VM. A controlled, prospective study of the effects of atorvastatin on proteinuria and progression of kidney disease. Am J Kidney Dis. 2003;41(3):565-70.

52. Hsu CY, McCulloch CE, Curhan GC. Epidemiology of anemia associated with chronic renal insufficiency among adults in the United States: results from the Third National Health and Nutrition Examination Survey. J Am Soc Nephrol. 2002;13(2):504-10.

53. Fink J, Blahut S, Reddy M, Light P. Use of erythropoietin before the initiation of dialysis and its impact on mortality. Am J Kidney Dis. 2001;37(2):348-55.

54. NKF-KDOQI. Clinical practice guidelines and clinical practice recommendations for anemia in chronic kidney disease in adults. Am J Kidney Dis. 2006;47(5 suppl 3): S16-S85.

55. Kausz AT, Guo H, Pereira BJ, Collins AJ, Gilbertson DT. General medical care among patients with chronic kidney disease: opportunities for improving outcomes. J Am Soc Nephrol. 2005;16(10):3092-101.

56. Besarab A, Bolton WK, Browne JK, et al. The effects of normal as compared with low hematocrit values in patients with cardiac disease who are receiving hemodialysis and epoetin. N Engl J Med. 1998;339(9):584-90.

57. Singh AK, Szczech L, Tang KL, et al. Correction of anemia with Epoetin alfa in chronic kidney disease. N Engl J Med. 2006;355(20):2085-98.

58. Drueke TB, Locatelli F, Clyne N, et al. Normalization of hemoglobin level in patients with chronic kidney disease and anemia. N Engl J Med. 2006; 355(20):2071-84

59. Perlman RL, Finkelstein FO, Liu L, et al. Quality of life in chronic kidney disease (CKD): a cross-sectional analysis in the Renal Research Institute-CKD study. Am J Kidney Dis. 2005;45(4):658-66.

60. Grimm G, Stockenhuber F, Schneeweiss B, Madl C, Zeitlhofer J, Schneider B Improvement of brain function in hemodialysis patients treated with erythropoetin. Kidney Int. 1990;38(3):480-86.
61. Levin A, Thompson CR, Ethier J, et al. Left ventricular mass index increase in early renal disease: impact of decline in hemoglobin. Am J Kidney Dis. 1999; 34(1):125-34

62. Roger SD, McMahon LP, Clarkson A, et al. Effects of early and late intervention with Epoetin alpha on left ventricular mass among patients with chronic kidney disease (stage 3 or 4): results of a randomized clinical trial. J Am Soc Nephrol. 2004;15(1):148-56.

63. Middleton RJ, Parfrey PS, Foley RN. Left ventricular hypertrophy in the renal patient. J Am Soc Nephrol. 2001;12(5):1079-84.

64. Levin A, Singer J, Thompson CR, Ross H, Lewis M. Prevalent left ventricular hypertrophy in the predialysis population: identifying opportunities for intervention. Am J Kidney Dis. 1996;27(3):347-54.

65. Weiner DE, Tighiouart H, Vlagopoulos PT, et al. Effects of anemia and left ventricular hypertrophy on cardiovascular disease in patients with chronic kidney disease. J Am Soc Nephrol. 2005;16(6):1803-10

66. Abramson JL, Jurkovitz CT, Vaccarino V, Weintraub WS, McClellan W. Chronic kidney disease, anemia, and incident stroke in a middle-aged, community-based population: the ARIC Study. Kidney Int. 2003;64(2):610-15.

67. Astor BC, Coresh J, Heiss G, Pettitt D, Sarnak MJ. Kidney function and anemia as risk factors for coronary heart disease and mortality: the Atherosclerosis Risk in Communities (ARIC) Study. Am Heart J. 2006;151(2):492500 .

68. Jurkovitz CT, Abramson JL, Vaccarino LV, Weintraub WS, McClellan WM. Association of high serum creatinine and anemia increases the risk of coronary events: results from the prospective community-based atherosclerosis risk in communities (ARIC) study. J Am Soc Nephrol. 2003;14(11):2919-25.

69. McClellan WM, Flanders WD, Langston RD, Jurkovitz C, Presley R. Anemia and renal insufficiency are independent risk factors for death among patients with congestive heart failure admitted to community hospitals: a population-based study. J Am Soc Nephrol. 2002;13(7):1928-36.

70. Vlagopoulos PT, Tighiouart H, Weiner DE, et al. Anemia as a risk factor for cardiovascular disease and all-cause mortality in diabetes: the impact of chronic kidney disease. J Am Soc Nephrol. 2005;16(11):3403-10.

71. Collins AJ. Anaemia management prior to dialysis: cardiovascular and costbenefit observations. Nephrol Dial Transplant. 2003;18(suppl 2):ii2-6.

72. Remuzzi G, Ingelfinger JR. Correction of anemia-payoffs and problems. N Engl J Med. 2006;355(20):2144-46

73. Levin A, Djurdjev O, Thompson C, et al. Canadian randomized trial of hemoglobin maintenance to prevent or delay left ventricular mass growth in patients with CKD. Am J Kidney Dis. 2005;46(5):799-811. 


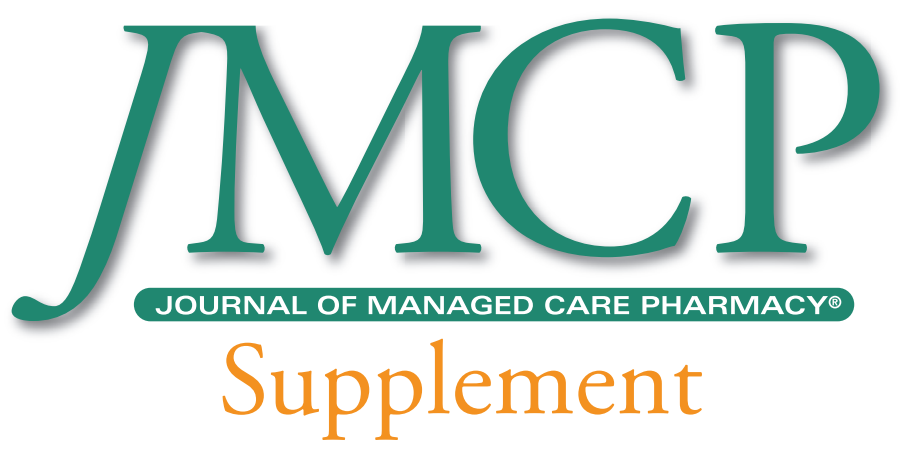

